Terbit online pada laman: http://teknosi.fti.unand.ac.id/

Artikel Penelitian

\title{
Pengujian dan Analisis Quality of Service Mobile Ad-Hoc Network (MANET) Menggunakan Protokol Routing Babel Pada Raspberry Pi
}

\author{
Shusmita Puspitasari ${ }^{a}$, Alif Subardono ${ }^{a}$, Ronald Adrian ${ }^{a}$ \\ ${ }^{a}$ Teknologi Rekayasa Internet, Universitas Gadjah Mada, Yogyakarta, 55281, Indonesia
}

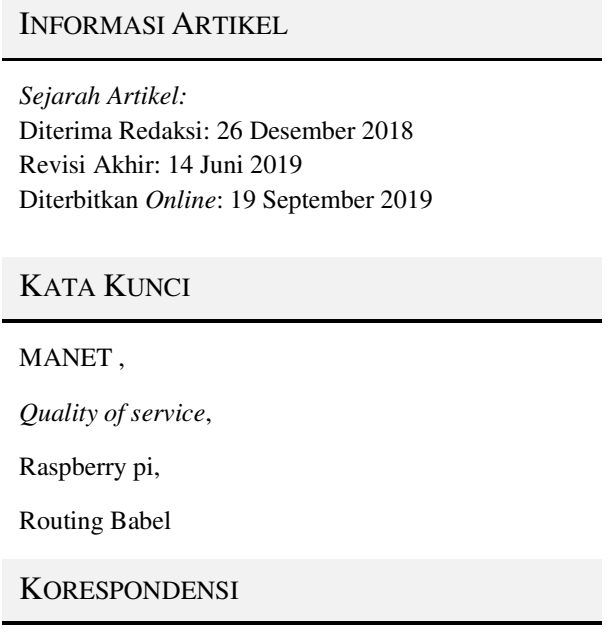

E-mail: shusmita.puspitasari@mail.ugm.ac.id

\section{A B S T R A C T}

Indonesia merupakan kawasan yang rawan bencana. Selain menimbulkan korban, bencana alam juga meruntuhkan banyak infrastuktur, salah satunya infrastruktur komunikasi. Dengan adanya masalah komunikasi dengan infrastuktur yang terbatas seperti yang terjadi di daerah bencana, solusi yang dapat dilakukan adalah dengan membangun Mobile Ad-hoc Network (MANET) karena memerlukan infrastruktur yang sederhana. Pada tugas akhir ini dilakukan pengujian dan analisis kualitas layanan (Quality of service) pada MANET menggunakan perangkat raspberry pi serta routing protokol Babel. QoS mengacu kepada kemampuan jaringan untuk menyediakan layanan yang baik melalui teknologi dan infrastruktur tertentu yang bertujuan untuk pertukaran informasi agar tersampaikan dengan baik. Parameter yang dijadikan acuan dalam penelitian ini antara lain adalah delay, jitter, throughtput dan packet loss. Pengujian menggunakan topologi mesh dengan empat skenario, satu skenario dengan kondisi full connected dan tiga skenario dengan kondisi partial connected sekalian juga mengetahui mekanisme protokol yang digunakan, selain itu dilakukaan juga saat terjadi interferensi dan tidak terjadi interferensi. Secara keseluruhan, hasil kualitas layanan pada saat pengujian dengan skenario topologi kondisi full connected pada MANET yang dibangun, lebih baik dibandingkan dengan kondisi partial connected.

\section{PENDAHULUAN}

Perkembangan teknologi hingga saat ini sudah merambat ke berbagai bidang, tak terkecuali bidang komunikasi yang membuat pengguna sangat mudah dalam melakukan komunikasi, baik secara real-time ataupun tidak. Hanya dengan koneksi jaringan internet, para pengguna smartphone dapat melakukan komunikasi percakapan yang tanpa batas wilayah, dan dengan biaya yang murah Namun hal tersebut tidak terlepas dari konektivitas yang digunakan. Konektivitas nirkabel merupakan salah satu fitur konektivitas untuk melakukan komunikasi pada smartphone. Hal tersebut menunjukan bahwa pemampatan wireless adapter telah ada pada device saat ini. Keberadaan pemampatan wireless adapter tersebut dapat mendorong dalam membangun jaringan komunikasi lingkup kecil seperti Mobile Ad Hoc Network (MANET) [1]. MANET adalah cara komunikasi kumpulan nirkabel node Mobile (smartphone atau laptop) yang dinamis dimana berfungsi sebagai jaringan tanpa menggunakan infrastruktur apapun (stand alone) dan tidak teradministrasi terpusat [2].

https://doi.org/10.25077/ TEKNOSI.v5i2.2019.79-87
Secara geografis, Indonesia merupakan negara kepulauan yang berada di lingkaran Cincin Api Pasifik (Ring of Fire). Koordinator Ikatan Ahli Geologi Indonesia (IAGI) Maluku Utara, Deddy Arif, mengatakan bahwa cincin api Pasifik merupakan daerah yang sering mengalami gempa bumi dan letusan gunung berapi yang mengelilingi cekungan Samudra Pasifik. Cincin api Pasifik berbentuk seperti tapal kuda dan mencakup wilayah sepanjang $40.000 \mathrm{~km}$. Tak heran indonesia menjadi kawasan yang rawan bencana. Badan Nasional Penanggulangan Bencana (BNPB) mencatat kecenderungan bencana di Indonesia sejak tahun 2010 hingga bulan Desember 2017 [3], rata-rata minimal 1.000 bencana terjadi di Indonesia setiap tahunnya. BNPB mencatat jumlah bencana yang terjadi mencapai 1681 sepanjang tahun 2015 lalu 2.384 kejadian bencana dari awal tahun hingga akhir tahun 2016 kemudian dari awal tahun hingga hingga 19 Desember 2017 bencana yang terjadi mencapai 2.271 .

Selain menimbukan korban, bencana juga meruntuhkan banyak infrastuktur, salah satunya infrastruktur komunikasi. Infrastuktur 
komunikasi digunakan untuk koordinasi penanganan pasca bencana dan penanggulangan jika terjadi bencana susulan pada daerah tersebut. Dengan adanya masalah komunikasi dengan infrastuktur yang terbatas seperti yang terjadi di daerah bencana, MANET menjadi salah satu solusi yang menjanjikan dari para peneliti bidang teknologi informasi dan komunikasi untuk dapat melakukan pertukaran informasi karena memerlukan infrastruktur yang sederhana dan memanfaatkan node yang dapat berfungsi sebagai host maupun sebagai router. Maka dari itu pada tugas akhir ini dilakukan pengujian dan analisis Kualitas layanan (Quality of service) pada MANET dengan traffic VoIP menggunakan routing babel untuk mengetahui seberapa baik layanan sistem komunikasi terhadap jaringan nirkabel di MANET.

Ad-hoc merupakan kumpulan dari beberapa wireless Mobile nodes atau router yang secara dinamis membentuk jaringan sementara tanpa menggunakan existing Network infrastructure atau adminitrasi terpusat (centralized administration). Router bebas bergerak secara acak dan mengatur dirinya secara bebas; dengan demikian topologi jaringan dapat berubah secara cepat dan tak terduga [4].

Mobile Ad-hoc Network (MANET) merupakan jaringan salah satu jaringan Adhoc yang yang terdiri dari sekumpulan perangkat bergerak yang dapat melakukan komunikasi satu dengan yang lainnya melalui jaringan nirkabel. Setiap perangkat yang biasa disebut node pada jaringan ini dilengkapi dengan antenna omni directional. MANET memungkinkan tiap node untuk melakukan routing seperti fungsi router pada umumnya yaitu menentukan dan meneruskan jalur komunikasi antar node. Nodenode yang berada dalam jaringan dapat bergerak bebas.

Dua node yang bergerak dan berada dalam jangkauan transmisi masing-masing dapat berkomunikasi secara langsung, jika tidak, node yang berada di antara keduanya harus dapat meneruskan paket agar berhasil berkomunikasi. Untuk meneruskan paket data dari sumber ke tujuan, setiap node dalam jaringan harus bersedia berpartisipasi dalam proses penyampaian paket data. Sebuah file tunggal dibagi menjadi sejumlah paket data dan kemudian paket data ini dikirim melalui jalur yang berbeda. Pada node tujuan, semua paket ini digabungkan secara berurutan untuk menghasilkan file asli [5].

Routing protokol pada jaringan ad-hoc terdapat tiga klasifikasi yaitu routing hybrid, routing reaktif dan routing proaktif. Protokol proaktif atau yang dikenal juga sebagai protokol tabel driven yang mempertahankan keterbaharuan topologi seluruh jaringan. Dengan bantuan peta ini, memudahkan protokol proaktif menemukan jalur yang sesuai dan optimal untuk pengiriman paket data ketika dibutuhkan. Protokol reaktif atau on demand akan memulai komunikasi berdasarkan permintaan dari node Mobile. Karena pertukaran paket terjadi ketika node siap, maka kepadatan paket dalam peta jaringan rute lebih rendah dibandingkan dengan protokol routing proaktif di mana jaringan dibanjiri sepanjang waktu dengan paket-paket untuk pemantauan berkala perubahan dalam peta rute [6]. Sedangkan protokol routing hybrid merupakan gabungan protokol routing dari protaktif dan reaktif untuk mencari jalur terbaik sesuai dengan permintaan dan kondisi (on demand) jaringan yang terus diperbaharui. Sementara itu, protokol UDP digunakan dalam penelitian ini. UDP ini juga tidak memerlukan congestion control pada koneksinya. Maksudnya adalah UDP dapat mengirimkan per segment tanpa dipengaruhi oleh kesibukan jaringan [7].

Menurut International Telecommunication Union Telecom (ITUT), organisasi standarisasi telekomunikasi dunia, Quality of service (QoS) merupakan Totalitas karakteristik layanan telekomunikasi yang memikul kemampuannya memenuhi kebutuhan yang dinyatakan dan tersirat dari pengguna layanan. Quality of service dapat diukur secara objektif dengan parameter seperti delay, jitter, throughtput, dan packet loss.

Throughput adalah kemampuan transfer data yang sebenarnya suatu jaringan dalam melakukan pengiriman data yang diukur dengan satuan bps (bit per second). Throughput dapat dihitung dengan melihat jumlah paket yang datang terhadap yang dikirim. Throughput juga merupakan kemampuan sebenarnya suatu jaringan dalam melakukan pengiriman data.

$$
\text { Throughput }=\frac{\text { Jumlah data yang dikirim (bit) }}{\text { Waktu Pengiriman }(\mathrm{sec})}
$$

Delay merupakan waktu yang dibutuhkan sistem dalam melakukan transmisi data dari pengirim ke penerima dengan satuan second (detik). Waktu delay end-to-end adalah jumlah waktu tunda konversi suara analog ke digital, waktu tunda waktu paketisasi atau bisa disebut juga waktu tunda panjang paket dan waktu tunda jaringan pada saat $\mathrm{t}$ (waktu) tertentu. Berikut adalah rumus perhitungan delay dan parameter kualitas delay:

$$
\text { Delay }=\frac{\text { Total delay }}{\text { Total paket yang diterima }}
$$

Tabel 1. Parameter Delay berdasarkan (TIPHON)

\begin{tabular}{cc}
\hline Katergori Delay & Delay $(\mathbf{m s})$ \\
\hline Sangat Bagus & $<150 \mathrm{~ms}$ \\
\hline Bagus & $151 \mathrm{~ms}-300 \mathrm{~ms}$ \\
\hline Sedang & $301 \mathrm{~ms}-450 \mathrm{~ms}$ \\
\hline Jelek & $>450 \mathrm{~ms}$ \\
\hline
\end{tabular}

Jitter merupakan perbedaan antara waktu kedatangan pake data dari pengirim ke penerima. Besarnya nilai jitter mengakibatkan rusaknya data yang diterima, baik itu berupa penerimaan yang terputus-putus atau hilangnya data akibat overlap dengan paket data yang lain [1].

Tabel 1. Parameter jitter [8]

\begin{tabular}{cc}
\hline Katergori Jitter & Jitter $(\mathbf{m s})$ \\
\hline Sangat Bagus & $0 \mathrm{~ms}$ \\
\hline Bagus & $1 \mathrm{~ms}-75 \mathrm{~ms}$ \\
\hline Sedang & $76 \mathrm{~ms}-125 \mathrm{~ms}$ \\
\hline Jelek & $126 \mathrm{~ms}-225 \mathrm{~ms}$ \\
\hline
\end{tabular}


Packet loss adalah banyaknya paket yang hilang pada suatu jaringan paket yang disebabkan oleh Collision. Adanya packet loss memiiki pengaruh langsung terhadapat data yang akhirnya disajikan kepada penerima. Berikut adalah rumus perhitungan packet loss dan dan parameter kualitas packet loss :

Packet Loss $=\frac{\text { Total packet loss yang terekam-packet loss terkirim }}{\text { Total packet loss terekam }} \times 100 \%$

Tabel 3. Parameter packet loss [8]

\begin{tabular}{cc}
\hline Katergori Packet Loss & Packet Loss (\%) \\
\hline Sangat Bagus & $0 \%-2 \%$ \\
\hline Bagus & $3 \%-14 \%$ \\
\hline Sedang & $15 \%-24 \%$ \\
\hline Jelek & $>25 \%$ \\
\hline
\end{tabular}

\section{METODE}

Metode yang digunakan pada penelitian ini adalah metode penelitian secara percobaan (experimental research). Dalam melaksanakan penelitan ini, terdapat tujuh tahapan yang terdiri dari (1) Studi literatur, (2) Perancangan jaringan, (3) Tahap instalasi, (4) Tahap implementasi, (5) Tahap pengujian jaringan, (6) Tahap pengambilan data, (7) Analisis hasil. Berikut adalah flowchart metode pada penelitian ini.

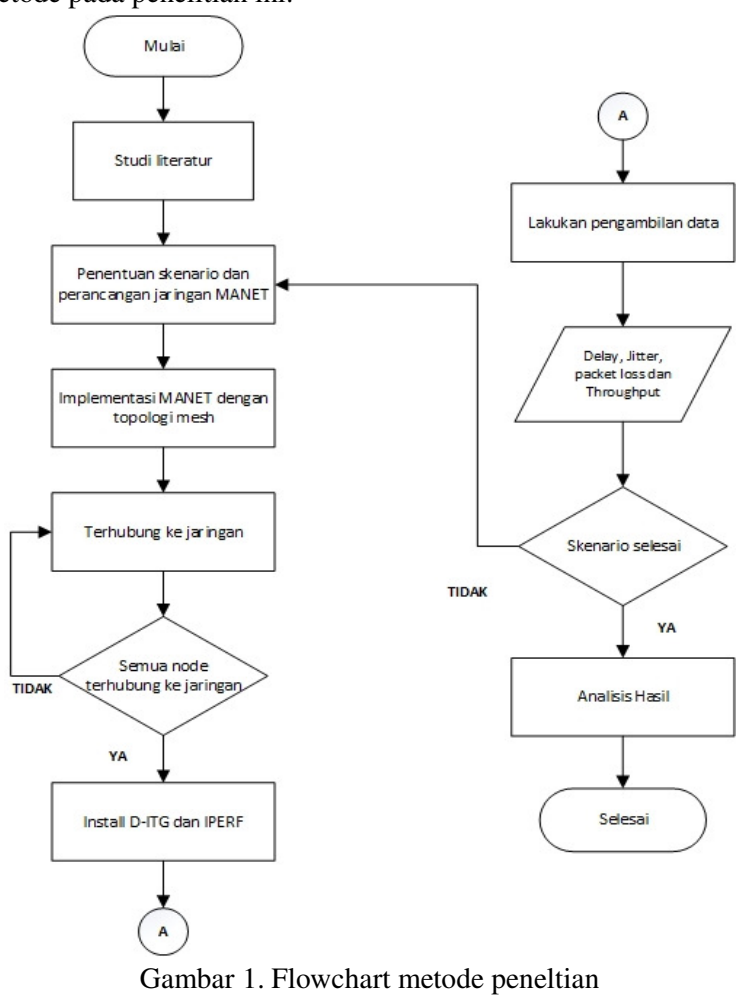

Berdasarkan pada flowchart metode peneltian yang terdapat pada gambar 1, maka dapat dijabarkan tahapan-tahapan pengujian yang akan dilakukan pada proyek akhir ini, sebagai berikut :

1. Studi literatur. Tahap pertama yang dilakukan dalam penelitian ini adalah mempelajari literatur tentang jaringan ad-hoc, routing protokol dan QoS data.

2. Perancangan jaringan. Tahap kedua yang akan dilakukan adalah merancang topologi yang terbaik, merancang jaringan yang akan digunakan, dan skenario yang akan dijalankan.

3. Tahap instalasi. Pada tahap ini dilakukan instalasi Operating System Raspbian Jessie versi 8.0 dengan menggunakan Win32DiskImager pada masing-masing microSD Card yang dimasukan ke dalam perangkat Raspberry Pi 3 Model B dan juga instalasi routing protokol babel. Kemudian melakukan instalasi D-ITG (Distributed Internet Traffic Generator) dan Iperf pada perangkat atau node yang menjadi client dan server.

4. Tahap implementasi. Pada tahap ini melakukan setting interface pada perangkat raspberry sehingga menjadi jaringan ad-hoc pada setiap perangkat. Lalu setelah semua di setting mejadi jaringan $a d-h o c$, menghubungkan semua node dengan mengaktifkan routing protokol babel.

5. Tahap pengujian jaringan. Setelah pada tahap implementasi melakukan setting jaringan ad-hoc dan menghubungkan semua node dengan mengaktifkan routing protokol, kemudian memastikan semua node benar-benar terhubung dengan yang lain sehingga dapat saling berkomunikasi.

6. Tahap pengambilan data. Pengambilan data pada penelitian ini dilakukan dengan bantuan tools D-ITG dan iperf.

7. Analisis hasil. Tahap ini merupakan tahapan terakhir, setelah memastikan semuanya berjalan sesuai dengan rancangan dan skenario. Analisis hasil dilakukan pada data keluaran pada penngujian. Data tersebut adalah data QoS dengan parameter delay, jitter, throughput, dan packet loss.

\subsection{Implementasi Sistem Pengujian}

\subsubsection{Perancangan Topologi}

Tabel 4. Konfigurasi IP setiap node

\begin{tabular}{ccc}
\hline Node & IP Address & Netmask \\
\hline Node A & 192.168 .2 .1 & 255.255 .255 .0 \\
\hline Node B & 192.168 .4 .1 & 255.255 .255 .0 \\
\hline Node C & 192.168 .5 .1 & 255.255 .255 .0 \\
\hline Node D & 192.168 .3 .1 & 255.255 .255 .0
\end{tabular}

Topologi yang digunakan pada pengujian dan analisa protoko routing Babel pada jaringan ad-hoc sebanyak satu jenis namun terdiri dari 4 skenario yang berbeda dengan. Skenario pada gambar 2, 3, 4 dan 5 skenario adalah skenario-skenario yang digunakan dan tabel 4 menunjukkan konfigurasi IP setiap node. 


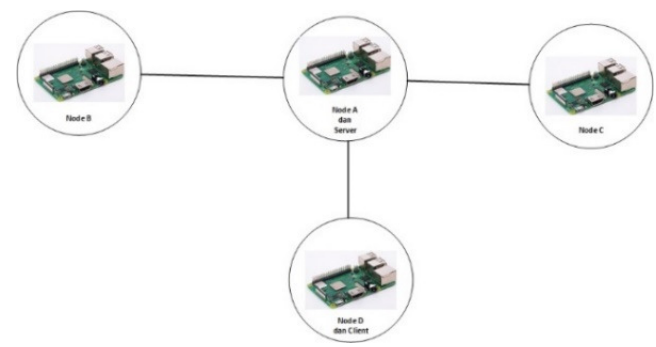

Gambar 2. Skenario 1

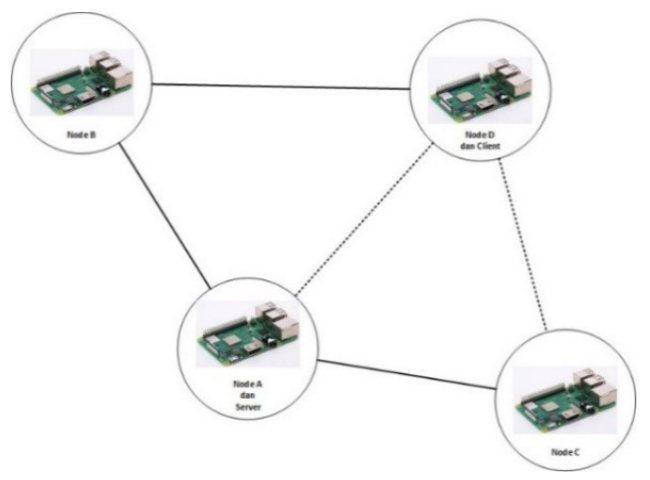

Gambar 3. Skenario 2

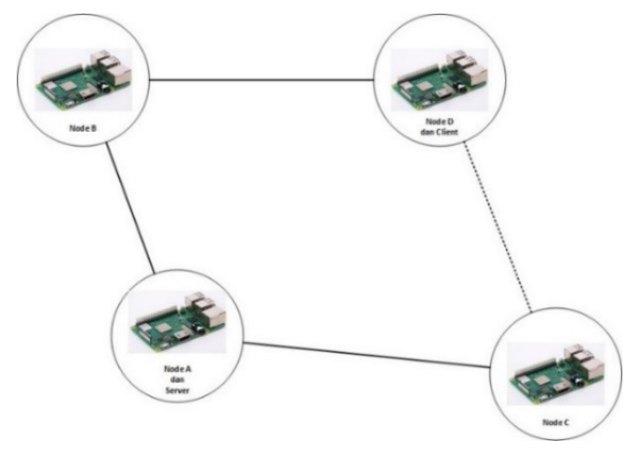

Gambar 4. Skenario 3

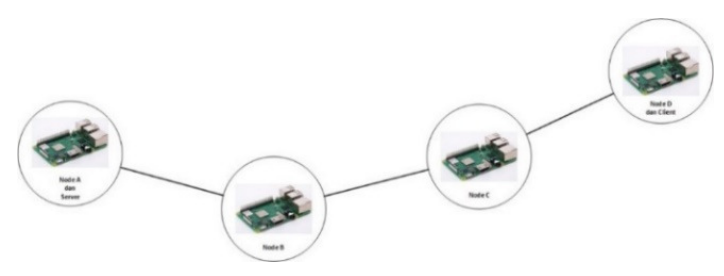

Gambar 5. Skenario 4

Pada pengujiannya setiap perangkat raspberry yang digunakan akan di setting menjadi jaringa ad-hoc sehingga dapat saling melakukan hubungan komunikasi antar perangkat atau node lain.

Seperti yang terlihat pada tabel 4 , konfigurasi ip address dan netmask jaringan ad-hoc ini menggunakan ipv4. Ip address pada empat node mannet tersebut memiliki Network yang berbeda beda. Seperti yang dimaksudkan untuk menguji fungsi routing dimana routing merupakan proses pemindahan data dari satu Network ke Network lain dengan cara mem-forward paket data melalui gateway [2]. IP address di konfigurasi secara static (tetap) supaya agar lebih mudah melakukan kontrol dan jika terjadi permasalahan pada jaringan ad-hoc seperti, salah satu node tidak tehubung dengan yang lain agar dapat lebih mudah melakukan throubleshooting (perbaikan) pada setiap perangkat atau node

\subsubsection{Konfigurasi Jaringan Ad-hoc}

Setelah melakukan instalasi operating sistem raspbian jessie pada semua perangkat raspberry berhasil, tampilahn halaman utamanya akan terlihat seperti gambar. Selanjutnya melakukan konfigurasi jaringan ad-hoc. Pertama buka commad promp atau terminal, lalu ketikan perintah pada file sudo nano /etc/network/interface.

\subsubsection{Instalasi Protokol Babel}

Tahap selanjutnya setelah melakukan konfigurasi jaringan ad-hoc adalah melakukan instalasi routing prokol Babel. Berikut adalah perintah untuk melakukan instalasi routing babel,

\section{sudo apt-get install babeld}

\subsubsection{Instalasi Babelweb}

Babelweb adalah interface web untuk memvisualisasikan rute Babel seperti terlihat pada gambar 6. Tool ini berfungsi untuk melakukan mapping topologi yang sedang terjadi saat sekarang secara realtime. Babel menggunakan banyak jenis pesan kontrol untuk mempertahankan grafik jaringan [8]. Langkah pertama yaitu melakukan instalasi node packet manager (NPM) untuk melacak semua paket dan versi tool dan memungkinkan untuk pengembang dengan mudah memperbarui atau menghapus ketergantungan ini.
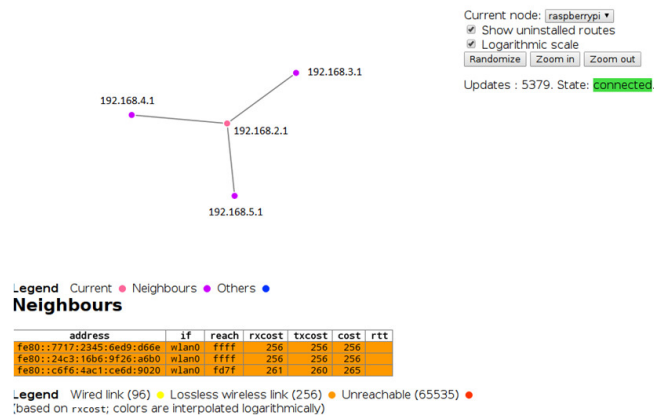

Gambar 6. Visualisasi rute babel

\subsubsection{Mengaktifkan Routing Protokol Babel dan Babelweb}

Setelah melakukan kofigurasi jaringan ad-hoc pada semua perangkat raspberry, kemudian akan melakukan mengaktifkan routing protokol babel agar semua node dapat saling terhubung satu dengan yang lainnya. Perintah untuk menjalakan routing protokol babel dapat dilihat pada gambar 7 . 
pieraspberrypi: \$ sudo babeld -d1 -w wlano

My id ba:27:eb:ff:fe:aa: 19:77 seqno 2702

192.168.2.1/32 metric 0 (exported)

169.254.147.234/32 metric 0 (exported)

My id ba:27:eb:ff:fe:aa:19:77 seqno 2702

192.168.2.1/32 metric 0 (exported)

$169.254 .147 .234 / 32$ metric 0 (exported)

My id ba:27:eb:ff:fe:aa: 19:77 seqno 2702

192.168.2.1/32 metric 0 (exported)

169.254.147.234/32 metric 0 (exported)

Gambar 7. Hasil pengaktifan routing babel

Tahap selanjutnya untuk menjalankan babelweb dapat dilihat pada gambar 8.

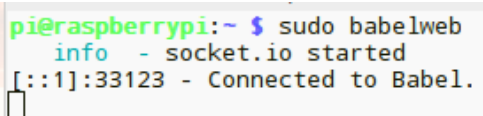

Gambar 8. Hasil pengaktifan babelweb

\subsection{Skenario Pengujian Simulasi}

Hal pertama yang dilakukan pada skenario pengujian ini adalah membentuk jaringan ad-hoc pada setiap perangkat raspberry berdasarkan perancangan topologi. Kemudian pengujian dilakukan dengan menggunakan tools D-ITG, iperf, dan traceroute. Tools DITG dan Iperf harus terpasang pada minimal dua host yang akan bertindak sebagai client dan server, dua tool ini memiliki kemampuan untuk membangkitkan trafik antar host atau dari client ke server. dengan menggunakan routing protokol babel, parameter Quality of service (QoS) antara lain, delay, jitter, throughput dan packet loss. Pengujian juga dilakukan dengan adanya perbedaan variabel jarak yaitu under normal, normal dan over normal, sekalian juga mengetahui mekanisme protokol yang digunakan. Lokasi pengujian akan sangat mempengaruhi kinerja dari pengiriman data melaui media wireless, karena media wireless yang digunakan pada penelitian ini merupakan media yang sangat mudah dipengaruhi oleh situasi atau keadaan sekitarnya.

Proses pengukuran pada skenario ini dilakukan dengan mengalirkan trafik UDP dan trafik background dari satu node ke node yang lain untuk membanjiri packet. Trafik UDP dihasilkan dari D-ITG, sedangkan trafik background dihasilkan oleh Iperf. Kemudian untuk background traffic yang dialirkan sebesar 1, 10, 20, - 80 Mpbs. Semua trafik tersebut diukur dengan topologi yang menggunakan 4 node atau perangkat raspberry. Setiap skenario topologi dilakukan 5 kali pengambilan

\section{HASIL DAN PEMBAHASAN}

Pada penelitian ini, dilakukan pengukuran terhadap empat parameter QoS yaitu delay, jitter, throughput dan packet loss pada topologi mesh dengan empat skenario, satu skenario dengan kondisi full connected dan tiga skenario dengan kondisi partial connected perbedaan variabel kondisi yang didapatkan dari hasil visualisasi topologi. Hasil pengujian QoS akan disajikan dalam bentuk diagram batang agar lebih mudah dalam menganalisa.

Skenario pengujian tugas akhir ini berdasarkan pada parameter yang digunakan untuk mengukur kinerja VoIP pada jaringan ad-hoc

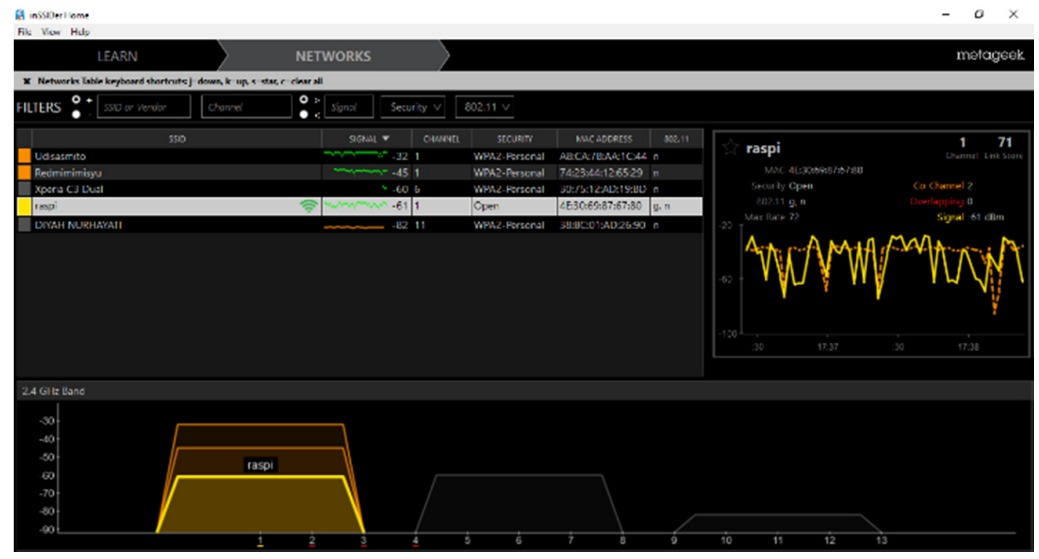

Gambar 9. Pengujian dengan interferensi

\subsection{Quality of service}

Pengujian quality of service (QoS) berfungsi untuk mengetahui kemampuan jaringan untuk menyediakan layanan yang baik melalui teknologi dan infrastruktur tertentu yang sehingga pertukaran informasi tersampaikan dengan baik. Parameter Qos yang akan diukur pada penelitian ini adalah delay, jitter, throughput dan packet loss. Kemudian pengujian QoS tersebut juga dilakukan di dalam ruangan dengan empat skenario, satu skenario dengan kondisi full connected dan tiga skenario dengan kondisi partial connected serta dengan keadaan terjadi interferensi dan tidak terjadi interferensiJaringan Mobile ad-hoc saat pegujian dibangun dengan menggunakan SSID raspi dan channel 1. Seperti yang terlihat pada 
gambar 9, jaringan nirkabel yang menggunakan channel 1 pada ruangan pengujian terdapat tiga jaringan, salah satunya adalah jaringan ad-hoc yang akan diujikan dan dua jaringan yang berbeda channel namun masih satu band frekuensi dengan jaringan raspi. Adanya persamaan dalam satu band frekuensi channel yang saling tumpang tindih yang dapat mengubah sinyal ini dapat menyebabkan interferensi.

\subsubsection{Jitter}

Jitter merupakan perbedaan antara waktu kedatangan paket data dari pengirim ke penerima. Pada penelitian ini menggunakan empat skenario, satu skenario dengan kondisi full connected dan tiga skenario dengan kondisi partial connected serta dengan keadaan terjadi interferensi channel dan tidak terjadi interferensi channel. Pengujian interferensi ini dimaksudkan untuk mengetahui pengaruhnya terhadap kualitas layanan yang dikirimkan. Hasil pengujian jitter dengan saat tidak terjadi interferensi dan terjadi interferensi pada masing masing skenario dapat dilihat pada gambar 10, 11,12 dan 13 .

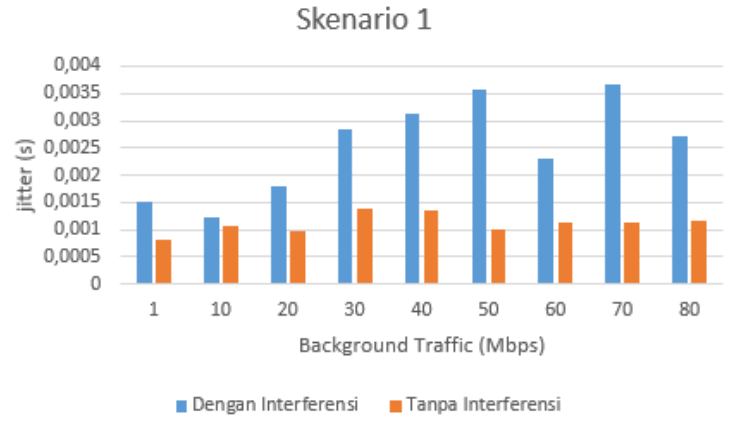

Gambar 10. Hasil pengujiann jitter pada skenario 1

Skenario 2

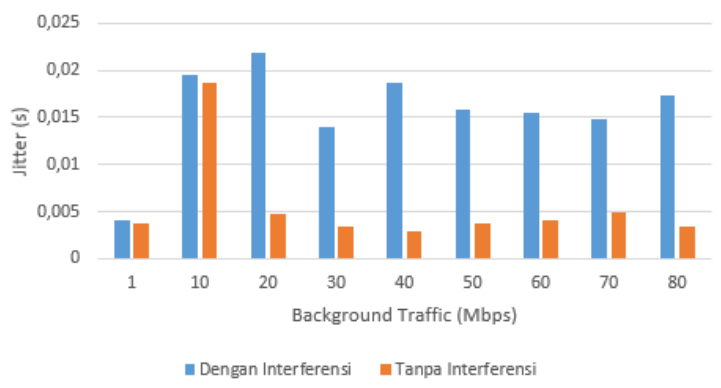

Gambar 11. Hasil pengujiann jitter pada skenario 2

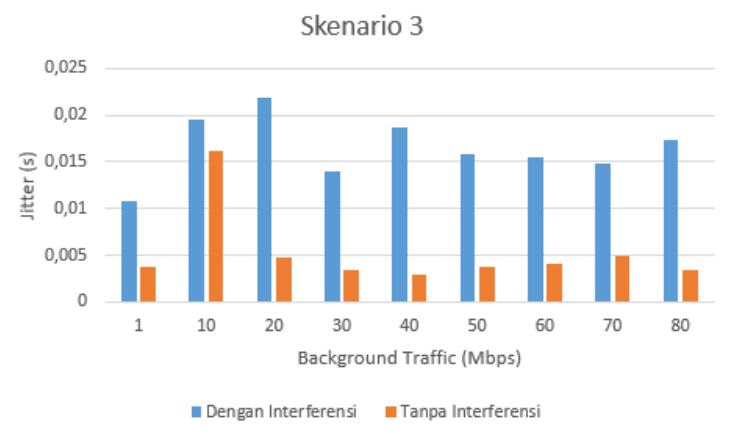

Gambar 12. Hasil pengujiann jitter pada skenario 3

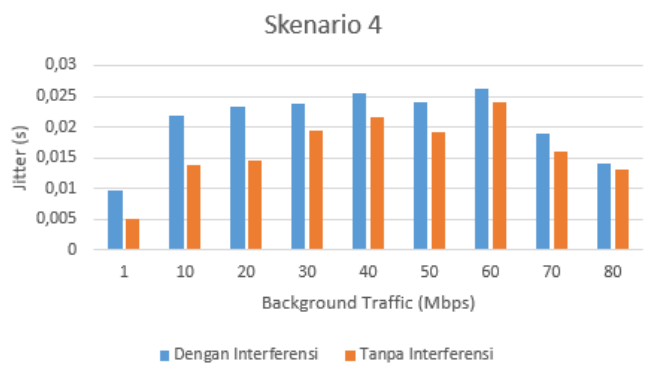

Gambar 13. Hasil pengujiann jitter pada skenario 4

Secara keseluruhan, nilai hasil jitter pada penelitian ini menurut Telecommunications and Internet Protocol Harmonization Over Networks (TIPHON) termasuk ke dalam kategori bagus dari skenario 1 hingga skenario 4 dengan pengujian yang terkena interferensi maupun tidak, karena nilai kategori bagus berkisar pada $0,001 \mathrm{~s}$ hingga $0,075 \mathrm{~s}$.

\subsubsection{Delay}

Delay merupakan waktu yang dibutuhkan sistem dalam melakukan transmisi data dari pengirim ke penerima dengan satuan second. Pada penelitian ini menggunakan empat skenario, satu skenario dengan kondisi full connected dan tiga skenario dengan kondisi partial connected serta dengan keadaan terjadi interferensi channel dan tidak terjadi interferensi channel. Hasil pengujian delay pada penelitian ini dapat dilihat pada gambar 14,15,16 dan 17 .

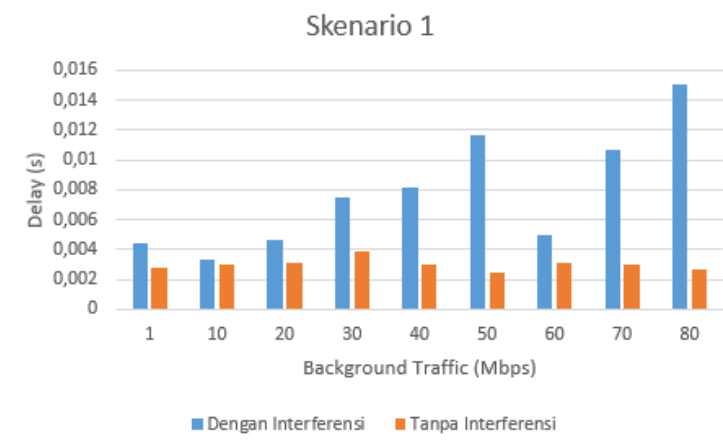

Gambar 14. Hasil pengujian delay pada skenario 1 
Skenario 2

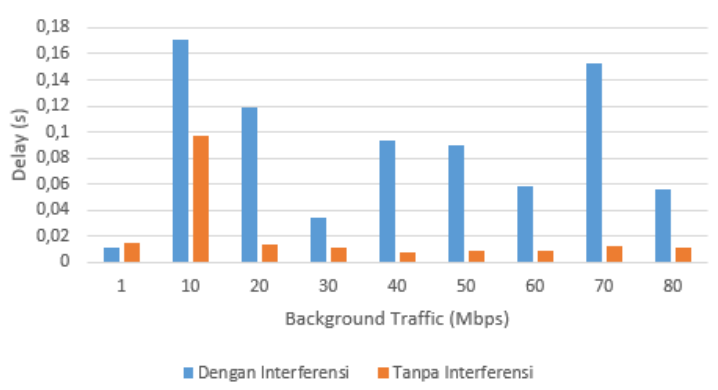

Gambar 15. Hasil pengujian delay pada skenario 2

Skenario 3

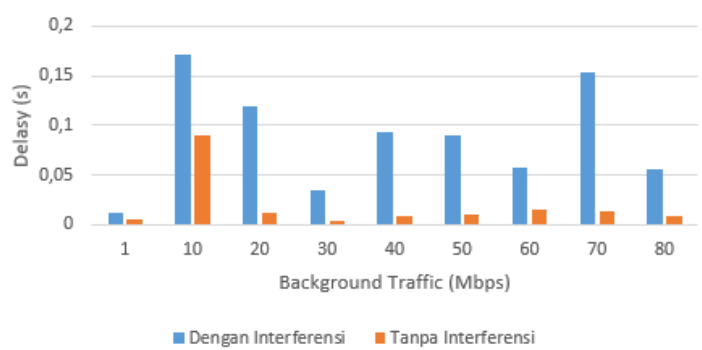

Gambar 16. Hasil pengujian delay pada skenario 3

Skenario 4

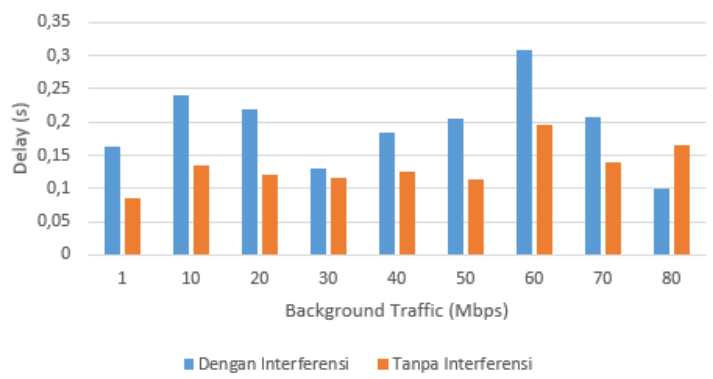

Gambar 17. Hasil pengujian delay pada skenario 4

Secara keseluruhan, nilai hasil delay pada penelitian ini menurut Telecommunications and Internet Protocol Harmonization Over Networks (TIPHON) termasuk ke dalam kategori bagus pada skenario 1 hingga skenario 3 dan skenario 4 termasuk kategori sedang dengan pengujian yang terkena interferensi maupun tidak. Nilai kategori bagus yaitu kurang dari 1,5 s dan nilai kategori sedang berkisar pada $1,51 \mathrm{~s}$ hingga $0,3 \mathrm{~s}$

\subsubsection{Throughput}

Throughput adalah kemampuan transfer data yang sebenarnya suatu jaringan dalam melakukan pengiriman data. Throughput juga merupakan kemampuan sebenarnya suatu jaringan dalam melakukan pengiriman data. Pada penelitian ini menggunakan empat skenario, satu skenario dengan kondisi full connected dan tiga skenario dengan kondisi partial connected serta dengan keadaan terjadi interferensi channel dan tidak terjadi interferensi channel.
Hasil pengujian throughput dapat dilihat pada gambar 18, 19, 20 dan 21.

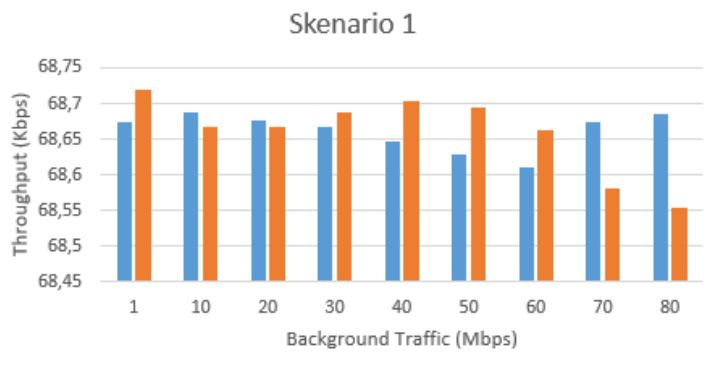

m Dengan Interferensi $\quad$ - Tanpa Interferensi

Gambar 18. Hasil pengujian throughput pada skenario 1

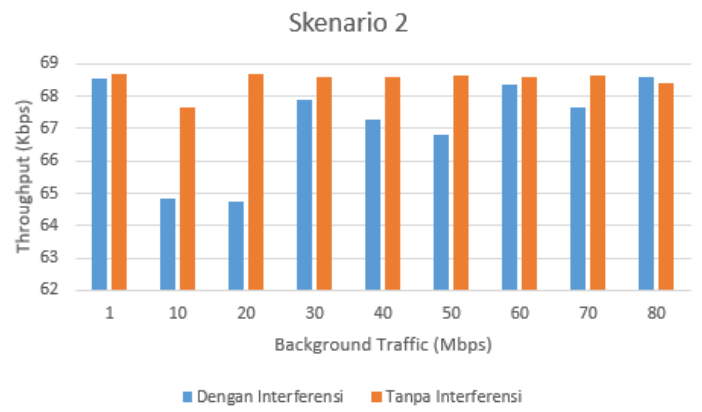

Gambar 19. Hasil pengujian throughput pada skenario 2

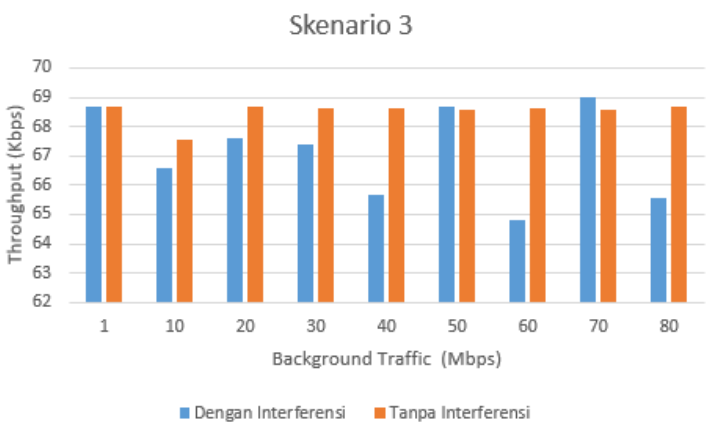

Gambar 20. Hasil pengujian throughput pada skenario 3

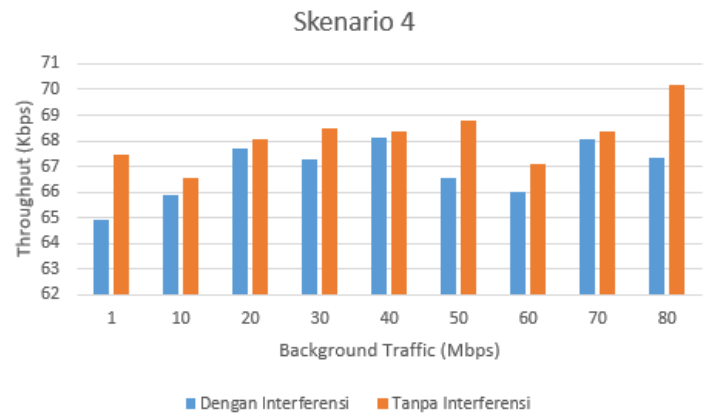

Gambar 21. Hasil pengujian throughput pada skenario 4 


\subsubsection{Packet loss}

Packet loss adalah banyaknya paket yang hilang pada suatu jaringan paket yang disebabkan oleh collision, penuhnya kapasitas jaringan, dan packet drop yang disebabkan oleh habisnya time to live paket. Pengujian packet loss dapat dilihat hasilnya pada gambar 22, 23, 24 dan 25 .

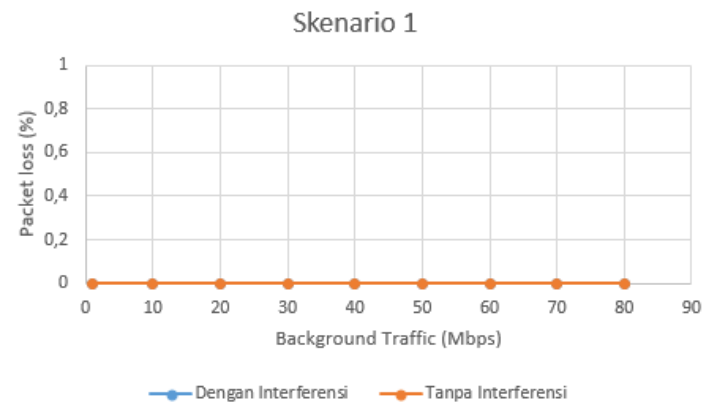

Gambar 22. Hasil pengujian packet loss pada skenario 1

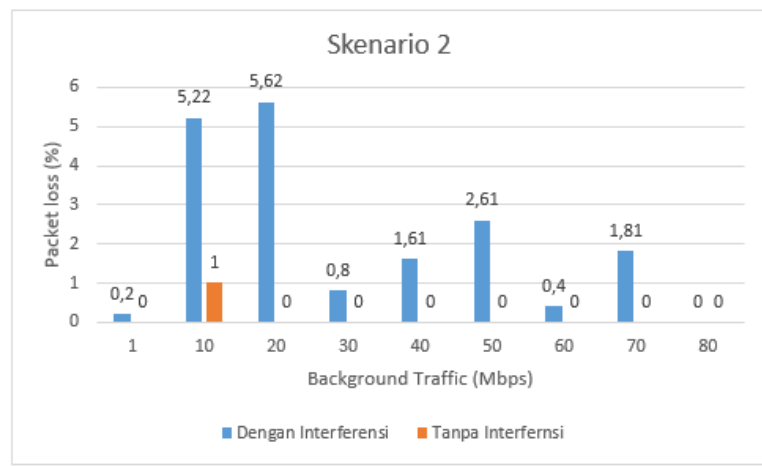

Gambar 23. Hasil pengujian packet loss pada skenario 2

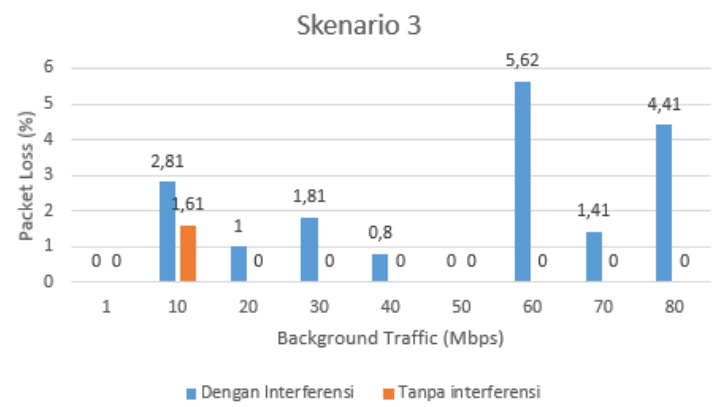

Gambar 24. Hasil pengujian packet loss pada skenario 3

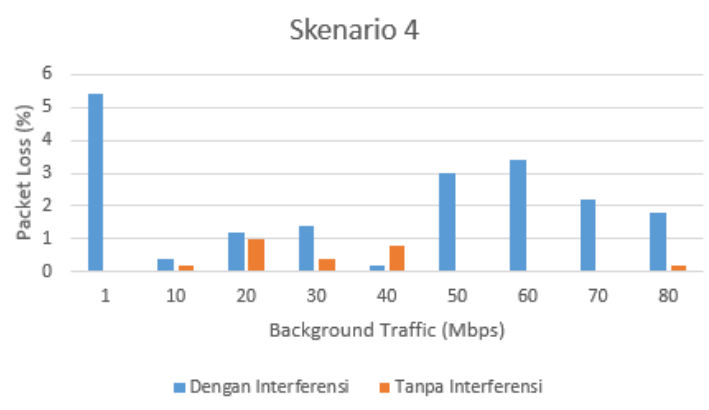

Gambar 25. Hasil pengujian packet loss pada skenario 4

Secara keseluruhan, nilai hasil packet loss pada penelitian ini menurut Telecommunications and Internet Protocol Harmonization Over Networks (TIPHON) termasuk ke dalam kategori sangat bagus dari skenario 1 hingga skenario 4 dengan pengujian yang terkena interferensi maupun tidak, karena nilai kategori sangat bagus berkisar pada $0 \%$ hingga $2,9 \%$.

\section{KESIMPULAN}

Berdasarkan hasil analisis pengujian kinerja Mobile Ad-hoc Network (MANET) dengan menggunakan routing protokol babel pada Raspberry pi, maka dapat disimpulkan bahwa Mobile ad-hoc Network dapat diimplementasikan dengan routing Babel pada perangkat Raspberry Pi 3 Model B. Interferensi memiliki pengaruh terhadap kualitas layanan yang dikirimkan. Hasil pengujian menunjukkan bahwa nilai delay, jitter, packet loss dan throughput terbaik secara keseluruhan dihasilkan pada skenario kondisi topologi full connected yaitu dengan nilai delay $0,002989556 \mathrm{~s}$, nilai jitter 0,001116667 s, nilai throughput 68,659453 Kbps dan nilai packet loss sebesar $0 \%$. Serta konektivitas antar node dalam MANET yang telah dibangun mampu bekerja dengan baik dalam kondisi 4 topologi yang berbeda-beda.

\section{DAFTAR PUSTAKA}

[1] R. A. Setyawan, "Analisis Unjuk Kerja Aplikasi VoIP Call Android di Jaringan MANET [Performance Analysis of VoIP Call Application Android in MANET (Mobile Ad Hoc Network)]," Bul. Pos Dan Telekomun., vol. 13, no. 1, pp 7996, Jun 2015.

[2] A. Wijayanto dan M. I. K. Ahmad Ashari., "Analisis Quality of Service (QoS) Routing Protocol Babel pada Mobile AdHoc Network (MANET),” Universitas Gadjah Mada, 2016.

[3] "Data Informasi Bencana Indonesia." [Daring]. Tersedia pada: http://bnpb.cloud/dibi/laporan. [Diakses: 09-Feb2018].

[4] S. K. Sarkar, C. Puttamadappa, dan T.G. Basavaraju, Ad hoc mobile wireless Networks: principles, protocols, and applications, 2 ed. CRC Press, 2016. 
[5] S. Adiwicaksono, "Deteksi Malicious Node pada Zone Routing Protocol di Jaringan Mobile Adhoc Network," Undergraduate, Institut Teknologi Sepuluh Nopember, 2017.

[6] M. Imran dan M. A. Qadeer, "Evaluation Study of Performance Comparison of Topology Based Routing Protocol, AODV and DSDV in MANET," dalam 2016 International Conference on Micro-Electronics and Telecommunication Engineering (ICMETE), 2016, pp 207211.

[7] A. Dwiyankuntoko, "Membandingkan Protokol UDP dan TCP,” 2007.

[8] ETSI, "Telecommunications and Internet Protocol Harmonization Over Networks (TIPHON); General aspects of Quality of Service (QoS).” 1999.

[9] V. Jacobson, R. Frederick, S. Casner, dan H. Schulzrinne, "RTP: A transport protocol for real-time applications," 2003.

[10] S. Sati dan A. El-bareg, "MANET Testbed using Raspberry PIs," Int. J. Wirel. Microw. Technol., vol. 8, no. 2, pp. 52, 2018. 